\title{
Pensions Act 2004: Effects on transactions involving UK companies
}

Received: 18th July, 2006

\section{John Papadakis}

is a partner in the London office of the international law firm, Jones Day, and heads the employee benefits and executive compensation practice in London. His pension practice covers all forms of corporate pension arrangements with a particular focus on the closure or windup of corporate pension plans. He is a member of the Association of Pension Lawyers and of the Share Plan Lawyers Organisation.

\section{Rosalind Connor}

is a senior associate in the employee benefits and executive compensation group of Jones Day in London, and specialises in advising corporates and trustees in relation to occupational pensions. She is a member of the Association of Pension Lawyers, and serves on its International sub-committee. She is also a member of the Plan Lawyers Organisation and is an associate of the Pensions Management Institute.

John Papadakis

Jones Day

21 Tudor Street

London EC4Y ODJ

Tel: +44 (0)20 70395272 Email: jjpapadakis@jonesday.com

\begin{abstract}
The Pensions Act 2004 has brought about the most radical changes to date to the regulation of pension plans in the UK. It has had a dramatic effect on the normal commercial activity of plan sponsors and investors, in particular in mergers and acquisitions and refinancing and restructuring involving UK companies. This paper analyses the effects of this legislation on corporate transactional activity and considers ways of tackling problems that may arise.
\end{abstract}

Keywords: UK pension plans, defined benefit, Pensions Regulator, contribution notice, financial support direction, employer liability

\section{The moral hazard provisions}

The provisions of sections $38-51$ of the Pensions Act 2004 ('the Act') — the so-called 'moral hazard' provisions caused an outcry among corporate Britain. The provisions permit the UK Pensions Regulator ('the Regulator') to impose liabilities for a pension plan on 'associated' and 'connected' parties of the sponsor of a defined benefit pension plan in certain circumstances.

The concept of parties other than the plan sponsor becoming liable for pension plan deficits is a radical change in the UK, where liability has always rested squarely with the plan sponsor.

The definitions of 'associated' and 'connected' parties for the purposes of the Act are broadly drawn and follow those used in the Insolvency Act 1986 for dealing with transactions that are assumed to be other than at arms-length prior to an insolvency. In particular, they include any director of the company, any party with a one-third shareholding or control over the board of directors of the company, and any party which has control through special rights, such as rights pertaining to a class of shares or rights as a special director of a company. Importantly, they include non-UK companies, which has encouraged the Regulator to look at international groups in relation to UK pensions issues. 
The Regulator has the power to impose liabilities in two very different situations.

\section{Contribution notice}

If the Regulator believes that the plan sponsor or any associated or connected party of that sponsor has acted, or failed to act, with a main purpose of that act or omission being the reduction of the liability that would be due from the sponsor to the pension plan on the plan's termination or to reduce the opportunity for full recovery of any such liability, it may issue a contribution notice to that party to make a payment into the plan.

The Regulator is required to consider intentions and motives in these circumstances and a wide range of activities may be considered. These may include a reorganisation that removes assets from a company or a group of companies, the payment of significant dividends, a stock buy-back or improving the security of a lender, such as a bank. Each of these actions may have the effect of reducing the chances of recovering any pensions liability and, therefore, the Regulator may consider the purposes behind those corporate actions.

The purpose test is not a test of absolute fact; the test is whether the Regulator believes (acting reasonably) that the negative impact on the pension plan was one of the main purposes of the action. Entirely innocent actions may open the possibility of a contribution notice if the Regulator believes them to be for such a purpose.

The requirement for the intention to reduce payments of the pension plan to be 'a main purpose' means that there is no complete defence in showing that there were other reasons for the action in question. It would have to be demonstrated that any negative impact on the pension plan was in fact incidental. For example, if the action in question involves the commercial sale of a global business including a small proportion relating to the $\mathrm{UK}$, that should be sufficient to show that issues relating to the UK pension plan (even if the employer covenant to the plan is weakened) are unlikely to be a main purpose of the transaction if the UK business and its pension liabilities are insignificant in the context of the transaction as a whole and no actions have been taken specifically to avoid those liabilities.

A contribution notice may also be issued in relation to any activity that has taken place at any time from 27 February, 2004 (the date on which this legislation was first announced in any detail). The Regulator has six years after any such event to issue a contribution notice. There is no detail in the legislation about the size of any contribution due under a notice but it is generally presumed that, as this is intended to be a punitive measure, the amount involved will be equal to the extent to which the liability to the pension plan, or the ability to recover it, is reduced.

\section{Financial support direction}

The Regulator also has the power to issue a financial support direction to any associated or connected parties of a pension plan sponsor where it believes that the plan sponsor itself is 'insufficiently resourced' to meet the plan's liabilities. 'Insufficiently resourced' means that the company has insufficient assets to meet 50 per cent of the liabilities of the plan calculated on the 'full buy-out' basis. The full buy-out basis is a very costly basis of calculating pension liabilities as the full buy-out 
deficit in a pension plan commonly exceeds the net assets of the plan sponsor. It is not particularly unusual for a plan sponsor to be insufficiently resourced on this basis and yet be able to finance a pension plan on an ongoing basis.

This is a 'no fault' measure; unlike a contribution notice, there is no requirement for the Regulator to believe that any untoward action has taken place which needs to be corrected. However, the Regulator is required not to impose a financial support direction when it would not be 'reasonable' to do so.

A financial support direction will require the associated or connected party to provide support to a pension plan by such method as is agreed with the Regulator. These methods may include an agreement to pay contributions, a guarantee of the liabilities of the plan sponsor or the grant of a lien over assets owned by that party in favour of the plan. If the party in receipt of the direction refuses or is unable to comply by means satisfactory to the Regulator, the Regulator may issue a contribution notice on that associated or connected party to require a specified contribution into the plan.

The Regulator may only issue a financial support direction in the twelve months following the date on which it holds the plan sponsor to be insufficiently resourced. Furthermore, if a party ceases to be an associated or connected party, once nine months have elapsed the Regulator is unable to issue a financial support direction on that party. Financial support directions may not be issued against individuals who are only associated or connected parties by reason of being an employee or officer (such as a director) of a company.

This legislation has had a dramatic effect on corporate transactions.

Transaction structures designed to ensure that pension liabilities are not acquired by purchasers and reconstructions to avoid insolvency have all come under close scrutiny. Smaller investors, private equity investors and creditors with the option of swapping debt for equity are particularly concerned about the effects of this legislation.

\section{Clearance procedure}

After extensive lobbying by the business community, the possibility of obtaining pre-clearance for proposed transactions was included in the Act. A clearance from the Regulator will prevent it from issuing a contribution notice in relation to the transaction for which clearance is being sought, or a financial support direction in relation to its present situation, so long as full facts and circumstances have been disclosed to the Regulator and those facts and circumstances do not change.

The Regulator has issued guidance on clearance procedures which explains the mechanics of the procedure, the circumstances in which the Regulator believes clearance should be sought, how the parties should conduct themselves when seeking clearance and the factors which will enable the Regulator to provide clearance (or not, as the case may be). Where clearance is not sought, it is expected that the Regulator will consider similar factors in deciding whether the moral hazard provisions should be invoked.

In particular, the Regulator views its role as empowering the plan trustees. Therefore, it expects the plan sponsor to communicate with the trustees as early as possible about the transaction in question and involve them in meaningful consultation, wherever possible obtaining their agreement to the changes being put in place, perhaps in return for a payment to or other security for the plan. 
The Regulator encourages applications for clearance, particularly in circumstances where:

- there is a change of ownership of the principal sponsor of the pension plan;

- there is a distribution of assets from the plan sponsor to shareholders; or

- liens are given over assets of the plan sponsor to a third party.

\section{Issues for the regulator}

When assessing the risk of the use of the moral hazard provisions by the

Regulator, it is important for an employer to consider what issues the Regulator is likely to take into account when deciding whether to issue a contribution notice or financial support direction. In particular, the Regulator will consider:

- Its statutory duty to protect the Pension Protection Fund. The Pension Protection Fund ('PPF') was established under the Act as a fund to take over the assets and liabilities of a pension plan, and to provide pensions for members, where its sponsor had become insolvent. The moral hazard provisions can be used to protect the PPF from having too many plans transferred to it. This is particularly important in rescue situations and also in straightforward insolvency where there are financially stronger companies that are connected or associated parties who may be called on to support the pension plan.

This has not prevented clearance being granted for business restructurings where one of the main consequences has been the transfer of the pension plan liabilities to the PPF. However, the Regulator has generally expected a payment into the pension plan and an equity stake for the PPF in the ongoing restructured business before granting clearance in these circumstances.

- Saving jobs. The Regulator has also indicated that it sees its role as protecting jobs. In many rescue situations or restructurings of groups of companies, it may be argued that the restructuring has been necessary in order to protect the workforce. For example, if the sale of a division has damaged the pension plan, but without the sale that division would have been wound up, leaving all its employees without work, the Regulator will consider and take into account the jobs to be saved in deciding whether or not to issue a contribution notice or financial support direction. This particular consideration has been of value for business restructuring specialists. The Regulator has, on occasion, been amenable to a restructuring which effectively moves assets away from the pension plan if it can be persuaded that this is the only way to obtain future investment or finance for the group and so allow the business and employment to continue. The earliest high profile example of this was the restructuring of Heath Lambert by way of the transfer of the business and assets of the solvent but troubled company without the pension plan, which was left in the old company. The old company would then become insolvent thereby forcing the pension plan into the PPF. Shares in the new company were to be held by the existing shareholders, at least one of which had a significant enough holding to be a potential recipient of a contribution notice. The Regulator cleared this proposal so long as a shareholding in the new company was given to the PPF when the plan entered the PPF. Criticism of this move was countered by the chairman of the Regulator on the grounds, 
among others, that 'the restructured company will protect employment'. Publicity following this clearance was mixed, and the Regulator has become less willing, at least in public, to justify clearances on the grounds of safeguarding jobs. The focus is now primarily on the duty to protect the PPF and the amount of cash and other equity available to the PPF.

- The behaviour of the sponsor towards the trustees. It is important that the trustees are brought into any discussions on a transaction as early as possible, subject to appropriate confidentiality undertakings. The trustees should also be encouraged to engage independent professional advice on the legal situation and, where appropriate, the financial situation of the company and the plan. If the trustees, having taken appropriate professional advice and being fully informed, have agreed to the transaction, the Regulator is less likely to interfere with the agreement. Even if the trustees have not agreed to the transaction, if the sponsor has shown itself to be reasonable in its negotiations with the trustees, it is more likely to obtain clearance on the basis of those negotiations.

\section{The attitude of the Regulator}

The Regulator was created under the Act to enforce these new powers. Previous pension plan regulation focused on compliance with legislative and administrative requirements. The new Regulator is much more proactive and its focus is on plans that may be in trouble either due to mismanagement or the financial insecurity of the sponsor. In these situations, it intends to be involved with the pension plan from an early stage and to guide the trustees to use whatever powers are at their disposal to secure and improve the financial position of the plan. The Regulator has yet to issue a contribution notice or financial support direction and sees this as evidence of its success as, it argues, parties have acted in compliance with the Regulator's wishes after the threat of the use of the Regulator's powers has been raised.

The Regulator's published guidance on clearance procedures, and more generally on the moral hazard provisions, has a number of inconsistencies with the terms of the legislation. In particular, its guidance on its clearance procedure focuses more on whether the transaction in contemplation weakens the financial standing of the sponsor and its group, without reference to the requirement for that weakening to have been 'a main purpose' of the transaction. Furthermore, the Regulator often suggests that a substantial payment into the pension plan by one of the parties to the transaction should be sufficient for it to grant clearance, despite the fact that this payment in itself does not affect the underlying increased difficulty in obtaining funds for the pension plan.

The Regulator initially took an expansive view of its ability to enforce a contribution notice overseas. In particular, it has argued that enforcement in the EU should not be difficult and has relied in these arguments on the Brussels Regulation (44/2001 EC). These regulations, however, relate to the enforcement in one EU member state of a judgment given in a court of another member state. Therefore, in order to enforce against an EU party, the Regulator would require the trustees of the relevant plan to take that party to the UK court to enforce the notice as a debt owed to the plan, which the trustees would then attempt to enforce in the other EU member state using the Brussels Regulation. Even if the trustees were willing to do this, there is some 
doubt as to the applicability of the Brussels Regulation in this scenario, where the judgment emanates originally from a statutory power of a public body. Practitioners are already seeing a retreat from the Regulator's initial position, and the Regulator is now focusing more on the financial strength of the UK group of companies. It should be noted that although the risk of a contribution notice or financial support direction being issued to a non-UK parent is receding, this does not mean that that company's other UK interests, held separately from the UK plan sponsor, are not also at risk through association with the non-UK parent.

The clear disparity between the legislation and the Regulator's guidance has resulted in some businesses not seeking clearance. Clearance is still not compulsory and there is a great disparity of views in the UK pensions industry as to whether clearance is appropriate where risk of the moral hazard provisions being correctly enforced is low.

There are certainly a number of situations in which companies may view clearance as inappropriate, costly and time-consuming. The requirement to ensure that the trustees are fully informed results in increased costs to the plan sponsor. The Regulator's tendency to require substantial payments into the pension plan as part of clearance for a transaction usually increases the cost of a transaction to a seller. In lower profile matters, where the risk of the Regulator's involvement is low, companies may decide against seeking clearance. High-profile matters have been viewed differently, particularly following the Ericsson Marconi deal. An announcement by Marconi that it would not be seeking clearance on its restructure and disposal was followed some time later with one stating that clearance had been granted, suggesting that the Regulator would take measures if it felt its powers were being ignored.

While clearance applications are not compulsory, and it is appropriate to consider their value before embarking on the time and cost they involve, there are some difficulties with deciding not to apply for clearance. In particular, although there is a disparity between the Regulator's guidance on the moral hazard provisions and the detail of the legislation, it is often not in the interests of the client, in terms of costs, time and publicity, for this disparity to be argued through the Pensions Regulator Appeals Tribunal and the High Court should clearance not be sought and a contribution notice be issued which does not appear to comply with the legislation. The Regulator also has strong political backing and its powers, if not wide enough under existing legislation, may be enhanced by primary or secondary legislation, and possibly with retrospective effect.

It is also important to be aware that there are obligations on the plan sponsor to notify the Regulator of certain events. In particular, a decision by a parent company of the plan sponsor to relinquish control of the sponsor is immediately notifiable to the Regulator. In transactions involving the sale of stock, in particular, it is unwise to assume that the Regulator will not be aware of a transaction and, therefore, not use its moral hazard powers.

\section{The practical effect on transactions}

As already mentioned, the effect of this legislation has been dramatic on UK corporate activity involving the sponsor of a defined benefit pension plan. It is necessary in all circumstances to consider the pension plan's liabilities, even when the transaction does not seem at first 
glance to bear any relevance to the pension plan.

The most noticeable change has been to the timing of transactions. The need to discuss issues with trustees and, wherever possible, reach agreement with them has slowed the closing of transactions. A certain level of agreement about the transaction needs to have been reached before the trustees are approached, otherwise it becomes difficult to negotiate with them effectively. On the other hand, if the transaction is fully agreed before it is presented to the trustees, the Regulator (and the trustees) may object that there has not been an appropriate level of consultation. Issues about conflicts of interest relating to senior company officers who act as trustees may also cause further delay.

It is very common for purchasers to ask for clearance ahead of any acquisition and often to have this as a condition of closing. From the purchaser's point of view, there is very little risk involved in a clearance application in these circumstances. If the Regulator refuses to give clearance or attaches conditions to it that the purchaser would find unacceptable, the purchaser may refuse to close.

The seller, on the other hand, suffers substantially. If clearance is not given, the sale may fall through and, at the same time, the Regulator's attention will have been turned to the pension plan, and the Regulator may, in any event, insist on additional funding for the plan or otherwise consider or threaten a financial support direction. The Regulator has shown itself willing and able to grant clearance in short timescales where necessary. Unless there is good cause for a short timeframe (eg a financial imperative attached to a specified date), clearance applications take at least three to four weeks and very often longer. The Regulator itself suggests that applicants for clearance allow a period of six weeks before deadlines.

It has become common for the Regulator to respond to clearance applications by asking in the first instance for funds to be paid into the plan in excess of those agreed between the plan sponsor and the trustees. However, a carefully considered and well reasoned application may succeed even where a contribution notice would, on the face of the legislation, be threatened.

The activity of the Regulator to date suggests that it is important to analyse very early on in transactions whether an application to the Regulator is appropriate. If the Regulator is to be approached, a well reasoned application following extensive discussion with the trustees greatly increases the chance and speed of success. 